\title{
Effect of Secukinumab on the Different GRAPPA-OMERACT Core Domains in Psoriatic Arthritis: A Pooled Analysis of 2049 Patients
}

\author{
Ana-Maria Orbai (D), Iain B. McInnes, Laura C. Coates, M. Elaine Husni, Dafna D. Gladman (D), \\ Laure Gossec, Luminita Pricop, Olivier Chambenoit, Xiangyi Meng, and Philip J. Mease
}

ABSTRACT. Objective. To compare the efficacy of secukinumab with that of placebo across the updated Group for Research and Assessment of Psoriasis and Psoriatic Arthritis and Outcome Measures in Rheumatology (GRAPPA-OMERACT) individual psoriatic arthritis (PsA) core domains using pooled data from 4 phase III PsA studies and 1 phase III ankylosing spondylitis (AS) study.

Methods. Data were pooled from 2049 patients with PsA participating in 4 on-label phase III PsA studies (FUTURE 2-5), and the efficacy of each GRAPPA-OMERACT PsA core domain (musculoskeletal disease activity, skin disease activity, pain, patient's global assessment, physical function, health-related quality of life, fatigue, and systemic inflammation) was assessed using multiple measures and definitions specific to each domain. The MEASURE 2 study, a phase III clinical trial in patients with AS, was used to assess improvement in spine symptoms at Week 16.

Results. Treatment with secukinumab demonstrated robust and consistent efficacy across all GRAPPA-OMERACT PsA core domains, with secukinumab $300 \mathrm{mg}$ showing the greatest response rates across most PsA core domains compared with placebo at Week 16. Notably, among patients treated with secukinumab $300 \mathrm{mg}, 34.3 \%$ and $19.5 \%$ achieved complete resolution of swollen and tender joint counts, respectively; $53.2 \%$ and $61.5 \%$ achieved complete resolution of enthesitis and dactylitis, respectively; and $33.2 \%$ achieved 100\% improvement in Psoriasis Area and Severity Index (all $\mathrm{p}<0.05$ vs placebo); similar improvements were shown for all other core domains.

Conclusion. This analysis suggests that secukinumab can benefit people with PsA across the clinical phenotypic spectrum commonly encountered in this disease. (First Release April 1 2020; J Rheumatol 2020;47:854-64; doi:10.3899/jrheum.190507)

Key Indexing Terms:

BIOLOGIC THERAPY INFLAMMATION INTERLEUKINS PSORIATIC ARTHRITIS

From the Johns Hopkins University School of Medicine, Baltimore, Maryland, USA; University of Glasgow, Glasgow; University of Oxford, Oxford, UK; Cleveland Clinic, Cleveland, Ohio, USA; Toronto Western Research Institute and University of Toronto, Toronto, Ontario, Canada; Sorbonne Université, Institut Pierre Louis d'Epidémiologie et de Santé Publique; Pitié Salpêtrière Hospital, AP-HP, Paris, France; Novartis Pharmaceuticals Corporation, East Hanover, New Jersey; Swedish Medical Center/Providence St. Joseph Health and University of Washington, Seattle, Washington, USA.

This study was funded by Novartis Pharmaceuticals Corp., East Hanover, New Jersey, USA, which manufactures secukinumab. A.M. Orbai is a Jerome L. Greene Foundation Scholar and is supported in part by a research grant from the US National Institute of Arthritis and Musculoskeletal and Skin Diseases of the National Institutes of Health under award number P30-AR070254 (Core B), a Rheumatology Research Foundation Scientist Development Award, and a Staurulakis Family Discovery Award.

A.M. Orbai has received grant support and consulting fees from Novartis. I.B. McInnes has received consulting fees from Novartis. L.C. Coates has received grant support, consulting fees, and speakers bureau fees from Novartis. D.D. Gladman has received grant support and consulting fees from Novartis. L. Gossec has received consulting fees from Novartis. L. Pricop, O. Chambenoit, and X. Meng are employees and stockholders of Novartis. P.J. Mease has received research grants, consulting fees, and speakers bureau fees from Novartis.

A.M. Orbai, MD, MHS, Johns Hopkins University School of Medicine; I.B. McInnes, MD, PhD, University of Glasgow; L.C. Coates, MBChB, PhD, University of Oxford; M.E. Husni, MD, MPH, Cleveland Clinic; D.D. Gladman, MD, FRCPC, Toronto Western Research Institute and University of Toronto; L. Gossec, $M D, P h D$, Sorbonne Université, Institut
Pierre Louis d'Epidémiologie et de Santé Publique, and Pitié Salpêtrière Hospital, AP-HP; L. Pricop, MD, Novartis Pharmaceuticals Corp.; O. Chambenoit, PhD, Novartis Pharmaceuticals Corp.; X. Meng, PhD Novartis Pharmaceuticals Corp.; P.J. Mease, MD, Swedish Medical Center/Providence St. Joseph Health and University of Washington.

Address correspondence to Dr. A.M. Orbai, Assistant Professor of Medicine, Johns Hopkins University School of Medicine, Division of Rheumatology, MFL Center Tower, Suite 4100, 5200 Eastern Ave., Baltimore, Maryland 21224,USA.E-mail: aorbai1@jhmi.edu

Full Release Article. For details see Reprints and Permissions at jrheum.org Accepted for publication September 27, 2019.

Psoriatic arthritis (PsA) is a rheumatologic disease involving the skin and musculoskeletal (MSK) system that affects about $25 \%$ of patients with psoriasis and $0.25 \%$ of people overall in the United States ${ }^{1}$. PsA manifests with skin and nail changes, peripheral joint inflammation, enthesitis, dactylitis, and axial involvement, either alone or in combination, resulting in pain, impaired physical function, and poor quality of life $(\mathrm{QOL})^{2}$. Most clinical studies of PsA use the American College of Rheumatology (ACR) response criteria for assessing treatment efficacy, mirroring clinical trials in rheumatoid arthritis (RA), although notably these criteria consider only the peripheral joints and may underdetect

Personal non-commercial use only. The Journal of Rheumatology Copyright (C) 2020. All rights reserved. 
the true value of a given agent in an individual with PsA, particularly regarding disease-specific manifestations ${ }^{3}$. The Group for Research and Assessment of Psoriasis and PsA (GRAPPA), in collaboration with Outcome Measures in Rheumatology (OMERACT), is currently seeking to improve and standardize assessments that are more specific to PsA outcomes ${ }^{4}$.

The PsA core domain set, initially implemented in $2006^{5}$, was updated in 2016 by GRAPPA with the endorsement of OMERACT ${ }^{4,6}$ to include the perspectives of both patients and physicians. The updated PsA core domains, required in all PsA clinical trials, are MSK disease activity (arthritis, enthesitis, dactylitis, and spine symptoms), skin disease activity (psoriasis and nail psoriasis), pain, patient's global assessment (PtGA), physical function, fatigue, health-related QOL (HRQOL), and systemic inflammation; structural damage assessment is recommended at least once in the development program of PsA medications (Figure 1) ${ }^{4}$.

Interleukin (IL)-17A is a proinflammatory cytokine that facilitates, directly and through synergism, several biological functions resulting in joint inflammation, joint erosion and new bone formation, and tissue remodeling, which are often, but variably, seen in $\mathrm{PsA}^{7,8}$. Treatment guidelines recommend targeting IL-17A as a therapeutic option to manage PsA in multiple domains ${ }^{9,10}$. Secukinumab, a fully human monoclonal antibody that selectively neutralizes IL-17A, has been proven safe and efficacious and was approved in multiple countries for the treatment of PsA and ankylosing spondylitis (AS) $)^{11,12,13,14,15,16}$. Studies have shown that patients treated with secukinumab had sustained improvements across multiple clinical domains ${ }^{11,12}$.

The aim of this posthoc analysis was to demonstrate the efficacy of secukinumab compared with placebo using the individual GRAPPA-OMERACT core domain set. Since the axial domain was not investigated in PsA ${ }^{11,12,13,14}$, we used the Bath Ankylosing Spondylitis Disease Activity Index (BASDAI) response in the AS MEASURE 2 study $^{15,16}$. To our knowledge, this is the first analysis to assess the response to a biologic therapy across each individual core domain.

\section{MATERIALS AND METHODS}

Study population. This posthoc analysis included patients with active PsA who participated in 4 on-label phase III clinical trials: FUTURE 2 ( $\mathrm{N}=397)$, FUTURE $3(\mathrm{~N}=414)$, FUTURE $4(\mathrm{~N}=341)$, and FUTURE $5(\mathrm{~N}=996)^{11,12,13,14}$. The full details of the study designs and patient enrollment criteria have been described previously ${ }^{11,12,13,14}$, and the trials are registered with ClinicalTrials.gov (FUTURE 2, NCT01752634; FUTURE 3, NCT01989468; FUTURE 4, NCT02294227; and FUTURE 5, NCT02404350). These studies were selected because they constituted the available data for secukinumab at the approved dose at the time this report was written. The FUTURE 1 study (NCT01392326) was excluded because

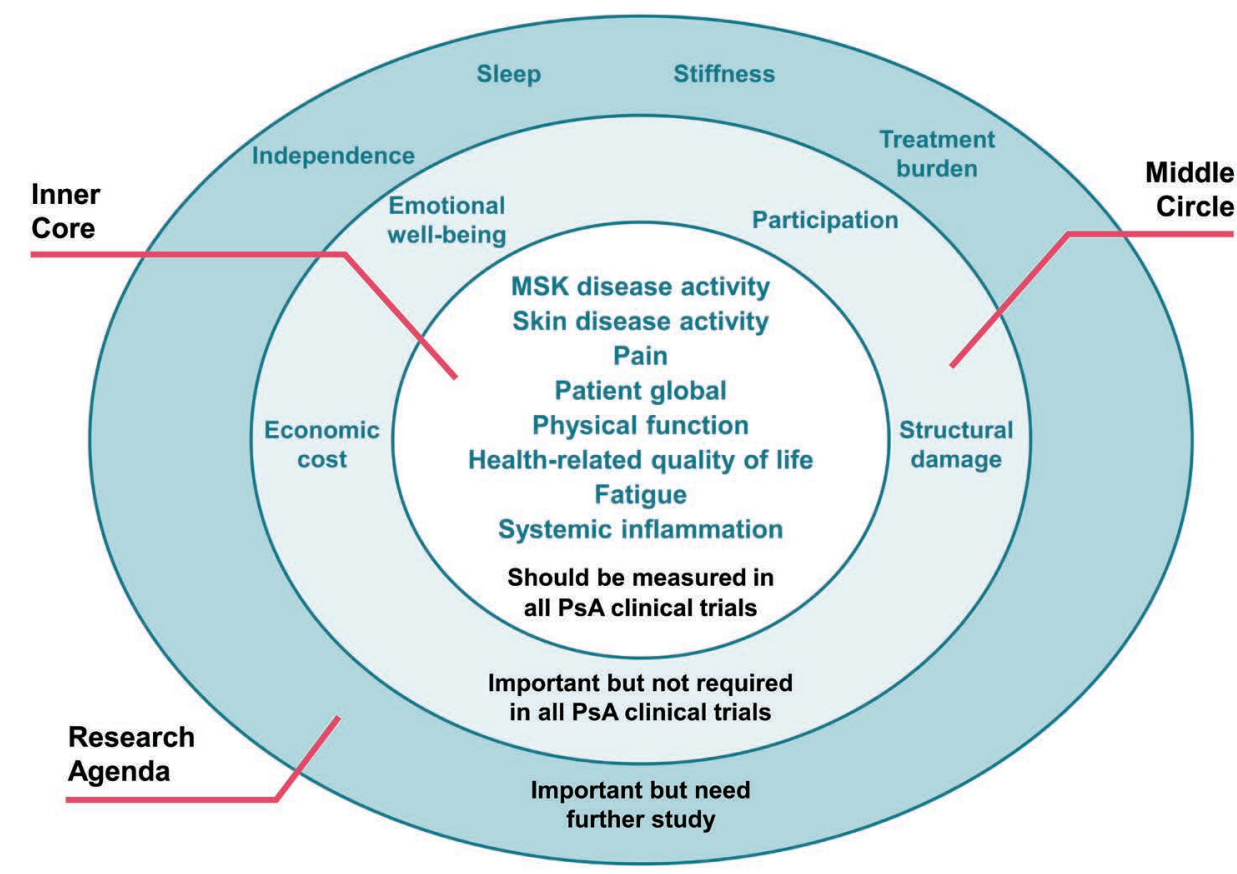

Figure 1. Updated 2016 PsA core domain set. MSK disease activity includes peripheral joints, enthesitis, dactylitis, and spine symptoms; skin activity includes skin and nails; patient global is defined as patientreported disease-related health status. The inner circle (core) includes domains that should be measured in all PsA randomized controlled trials and longitudinal observational studies. The middle circle includes domains that are important but may not be feasible to assess in all randomized controlled trials and longitudinal observational studies. The outer circle, or research agenda, includes domains that may be important but need further study. Reproduced from Orbai AM, et al. Ann Rheum Dis 2017;76:673-80, copyright 2017, with permission from BMJ Publishing Group Ltd. MSK: musculoskeletal; PsA: psoriatic arthritis. 
the intravenous loading dose is not approved for the treatment of PsA. All 4 of the included studies had a secukinumab $150 \mathrm{mg}$ subcutaneous load arm. FUTURE 2, 3, and 5 included a secukinumab $300 \mathrm{mg}$ subcutaneous load arm, and the FUTURE 4 and 5 studies each had a secukinumab $150 \mathrm{mg}$ no-load arm. All studies had a primary endpoint of a $20 \%$ improvement in ACR criteria (ACR20) at Week 16 or later and demonstrated a statistically significant higher proportion of patients achieving an ACR20 response in the secukinumab $150 \mathrm{mg}$ and $300 \mathrm{mg}$ groups than in the placebo group. Data were pooled according to the following treatment groups: secukinumab $150 \mathrm{mg}$ without loading administered at baseline and then every 4 weeks; secukinumab $150 \mathrm{mg}$ or $300 \mathrm{mg}$ with loading dose administered at baseline and weeks $1,2,3$, and 4 , followed by treatment every 4 weeks; or placebo until the end of the 16-week double-blind placebo-controlled period.

Because axial disease was not assessed in the FUTURE clinical trials, the MEASURE 2 study was used for hypothesis generation to assess the spine domain. In this phase III clinical trial, 72 patients with AS received secukinumab $150 \mathrm{mg}$ administered at baseline and weeks 1, 2, 3, and 4, followed by treatment every 4 weeks, and 74 patients received placebo over a 16-week period ${ }^{15,16}$. The full details of the study design and patient enrollment criteria have been described previously, and the trial is registered with ClinicalTrials.gov (NCT01649375) ${ }^{15}$.

All included studies were approved by each central institutional review board (IRB; FUTURE 2 approving board: Copernicus Group IRB date of approval: January 17, 2013, Copernicus IRB Tracking number: NOV2-12-439; FUTURE 3 approving board: Quorum IRB, date of approval: February 4, 2014; FUTURE 4 approving board: Chesapeake IRB, date of approval: December 12, 2014; FUTURE 5 approving board: Chesapeake IRB, date of approval: June 11, 2015; MEASURE 2 approving board: Copernicus Group IRB, date of approval: August 20, 2012, Copernicus IRB Tracking number: NOV2-12-263). Approval was also obtained from the ethics review boards of each additional center that participated in the individual studies. Written informed consent was obtained from all participants before study inclusion.

Outcomes and assessments. The efficacy of secukinumab in all domains of the updated GRAPPA-OMERACT PsA core domain set was evaluated at Week 16 using multiple instruments recorded in published clinical trials. MSK disease activity and Psoriasis Area and Severity Index (PASI) scores were evaluated using nonresponder imputation for missing data, and other outcomes were evaluated using as-observed data (Table 1). Efficacy for MSK disease activity subdomains (arthritis, enthesitis, dactylitis) was assessed using $\geq 50 \%$ improvement and complete resolution $(100 \%)$ in swollen joint count in 66 joints (SJC66), tender joint count in 68 joints (TJC68), Leeds Enthesitis Index ${ }^{17}$, and Leeds Dactylitis Index ${ }^{18}$. Efficacy for skin disease activity was assessed using $\geq 75 \%$ improvement (PASI75) and complete resolution (PASI100), 75\% improvement in the modified Nail Psoriasis Severity Index (mNAPSI75), and Investigator's Global Assessment (IGA) modified 2011 scores of 0 or 1 (clear or almost clear $)^{19}$. Efficacy for patient-reported outcomes was assessed as follows: for pain and PtGA by the mean change from baseline using a 100-mm visual analog scale (VAS) and achievement of $\mathrm{a} \geq 30 \%$ improvement in VAS scores; for physical function by mean change from baseline in the Health Assessment Questionnaire-Disability Index (HAQ-DI; scale, 0-3) and by achievement of the recalculated minimal clinically important difference (MCID) of $\geq 0.35$ in PsA ${ }^{20,21}$; for HRQOL using the MCID of $\geq 2.5$ in the raw Medical Outcomes Study Short Form-36 (SF-36) health survey physical component summary (PCS) and SF-36 mental component summary (MCS) scores established and used in $\mathrm{RA}^{22,23,24,25}$, and the mean change from baseline in the PsA quality of life (PsAQOL; scale 0-20) and

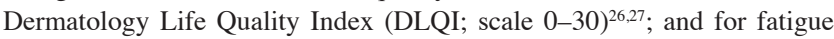
using the mean change from baseline in the Functional Assessment of Chronic Illness Therapy-Fatigue (FACIT-Fatigue; scale 0-52) scores and achievement of the FACIT-Fatigue response, defined as a change from baseline of $\geq 3.5^{4,28}$. Efficacy for overall activity impairment was assessed by the mean change from baseline in the respective Work Productivity and
Activity Impairment Questionnaire: General Health (WPAI:GH) domain. Efficacy for structural damage was evaluated by the achievement of no structural progression at Week 24, defined as a change from baseline in van der Heijde-modified total Sharp score (vdH-mTSS) of $\leq 0.5^{14}$. Efficacy for systematic inflammation was evaluated by the resolution of elevated C-reactive protein (CRP) levels at Week 16, defined as achievement of $\leq 10 \mathrm{mg} / \mathrm{l}$ among patients with CRP $>10 \mathrm{mg} / \mathrm{l}$ at baseline. Efficacy for improvements in spine symptoms was assessed at Week 16 in patients with AS who were enrolled in MEASURE 2 and included mean change from baseline and achievement of a $20 \%$ improvement and adequately controlled disease (defined as a score of $<4$ ) in the BASDAI and achievement of a $40 \%$ improvement in Assessment in SpondyloArthritis international Society response criteria (ASAS40) ${ }^{15}$.

Data analysis. Responses in individual core domains allowed for a granular view of secukinumab efficacy at the primary efficacy endpoint of 16 weeks, at approved doses. In this posthoc analysis, thresholds for meaningful improvement were defined previously for several outcome measures. Where meaningful improvement was defined for an outcome measure, that threshold was used. Where meaningful improvement was unknown, a threshold was selected that was judged to be significant based on current measures in use in clinical trials (e.g., a 50-75\% improvement) or the least squares mean change from baseline. For MSK disease activity subdomains and skin disease activity, responses corresponding to complete resolution (100\% improvement) are also shown. All p values were for hypothesis generation. No adjustment was made for multiple comparisons.

\section{RESULTS}

Baseline characteristics. This pooled analysis included 2049 patients from the FUTURE 2, 3, 4, and 5 studies, of whom 461 received secukinumab $300 \mathrm{mg}, 572$ received secukinumab $150 \mathrm{mg}, 335$ received secukinumab $150 \mathrm{mg}$ no load, and 681 received placebo. The pooled baseline demographics and disease characteristics were broadly similar in all treatment groups (Table 2). A mixed population of biologic-naive patients and those not responding adequately to tumor necrosis factor inhibitors (secukinumab $300 \mathrm{mg}$, $31.5 \%$; secukinumab $150 \mathrm{mg}, 30.2 \%$; secukinumab 150 $\mathrm{mg}$ no load, $27.2 \%$; placebo, $30.0 \%$ ) were enrolled in the studies.

Efficacy of secukinumab across GRAPPA-OMERACT PsA inner circle core domains. Across the MSK disease activity domain, patients treated with secukinumab $300 \mathrm{mg}$ achieved the greatest response rates, followed by secukinumab $150 \mathrm{mg}$ and secukinumab $150 \mathrm{mg}$ no load, all of which were significantly higher than placebo (Figure 2). A $\geq 50 \%$ improvement in SJC66 was seen in $68.8 \%$ of patients who received secukinumab $300 \mathrm{mg}, 62.1 \%$ of patients who received secukinumab $150 \mathrm{mg}, 59.4 \%$ of patients who received secukinumab $150 \mathrm{mg}$ no load, and $39.4 \%$ of patients who received placebo at Week 16 (all p vs placebo < 0.0001). Comparable results were also seen in TJC68 in all groups at Week 16, with the greatest number of patients demonstrating improvements in the secukinumab $300 \mathrm{mg}$ group; complete resolution of arthritis, as assessed by $100 \%$ improvement in SJC66 and TJC68, was observed in $34.3 \%$ and $19.5 \%$ of patients who received secukinumab $300 \mathrm{mg}$ (Figure 2A). Further, $53.2 \%$ of patients who received secukinumab 300 $\mathrm{mg}, 44.4 \%$ of patients who received secukinumab $150 \mathrm{mg}$,

Personal non-commercial use only. The Journal of Rheumatology Copyright @ 2020 . All rights reserved. 
Table 1. PsA outcome measures and prespecified endpoints for resolution and improvement.

Domain Measure

Inner Circle (core) Domains (should be measured in all PsA clinical trials)

Musculoskeletal disease activity (arthritis, enthesitis, dactylitis)

No. (\%) of patients achieving $\geq 50 \%$ improvement in SJC66, TJC68, LEI, and LDI

No. (\%) of patients achieving complete resolution in SJC66, TJC68, LEI, and LDI

Skin disease activity

No. $(\%)$ of patients achieving PASI100 or PASI75

No. (\%) of patients achieving IGA 0/1 (clear/almost clear)

No. $(\%)$ of patients achieving mNAPSI75

Spine symptoms (MEASURE 2; hypothesis-generating data from patients with AS)

Mean change from baseline in BASDAI

No. (\%) of patients achieving $20 \%$ improvement in BASDAI

No. $(\%)$ of patients achieving inactive disease (BASDAI < 4)

No. (\%) of patients achieving ASAS40 response

Pain

Patient's global assessment

LSM change from baseline in pain VAS (scale, $0-100$ )

No. (\%) of patients with $\geq 30 \%$ improvement in pain VAS

LSM change from baseline in patient global assessment (scale, 0-100)

No. (\%) of patients with $\geq 30 \%$ improvement in patient global assessment VAS

Physical function

Least squares mean change from baseline in HAQ-DI (scale 0-3)

HRQOL

No. (\%) of patients achieving MCID of $\geq 0.35$ in the HAQ-DI

No. (\%) of patients achieving MCID of $\geq 2.5$ in the SF-36 PCS and

SF-36 MCS

LSM change from baseline in PsAQOL (scale 0-20)

LSM change from baseline in DLQI (scale 0-30)

Fatigue

LSM change from baseline in FACIT-Fatigue score (scale 0-52)

No. (\%) of patients with $\geq 3.5$-point improvement in FACIT-Fatigue score (responder)

Systemic inflammation

Middle Circle Domains (important but not required in all PsA clinical trials)

Participation

Structural damage

No. (\%) of patients achieving resolution of elevated CRP levels $(\leq 10 \mathrm{mg} / \mathrm{l})$ among patients with baseline $\mathrm{CRP}>10 \mathrm{mg} / \mathrm{l}$

LSM change from baseline in WPAI:GH (\% impairment)

No. $(\%)$ of patients without structural progression (change from baseline $\mathrm{vdH}-\mathrm{mTSS}$ of $\leq 0.5)$

AS: ankylosing spondylitis; ASAS40: 40\% improvement in Assessment in SpondyloArthritis international Society response criteria; BASDAI: Bath AS Disease Activity Index; CRP: C-reactive protein; DLQI: Dermatology Life Quality Index; FACIT-Fatigue: Functional Assessment of Chronic Illness Therapy-Fatigue; HAQ-DI: Health Assessment Questionnaire-Disability Index; HRQOL: health-related quality of life; IGA: Investigator's Global Assessment modified 2011; LDI: Leeds Dactylitis Index; LEI: Leeds Enthesitis Index; LSM: least squares mean; MCID: minimal clinically important difference; MCS: mental component summary; mNAPSI75: 75\% improvement in the modified Nail Psoriasis Severity Index; PASI75/100: 75\%/100\% improvement in the Psoriasis Area and Severity Index; PCS: physical component summary; PsA: psoriatic arthritis; PsAQOL: PsA-specific quality of life; SF-36: Medical Outcomes Study Short Form-36 health survey; SJC66: swollen joint count based on 66 joints; TJC68: tender joint count based on 68 joints; VAS: 100-mm visual analog scale; vdH-mTSS: van der Heijde-modified total Sharp score; WPAI:GH: Work Productivity and Activity Impairment Questionnaire: General Health.

and $41.0 \%$ of patients who received secukinumab $150 \mathrm{mg}$ no load achieved complete resolution of enthesitis versus $29.0 \%$ of patients who received placebo (all p vs placebo $<0.05$; Figure 2B). Similarly, complete resolution of dactylitis was observed in $61.5 \%$ of patients who received secukinumab $300 \mathrm{mg}, 52.1 \%$ of patients who received secukinumab 150 $\mathrm{mg}$, and $52.5 \%$ of patients who received secukinumab 150 mg no load versus $32.9 \%$ of patients who received placebo (all $\mathrm{p}$ vs placebo $<0.05$; Figure $2 \mathrm{~B}$ ).

Similar results were also seen in the skin disease activity domain, with patients who received secukinumab $300 \mathrm{mg}$ demonstrating the greatest response rates across all skin and nail measurements. Complete resolution of psoriasis
(PASI100) and achievement of clear/almost clear skin (IGA $0 / 1$ ) by Week 16 was observed in $33.2 \%$ and $52.3 \%$ of patients in the secukinumab $300 \mathrm{mg}$ group, respectively (Figure 2C).

In the analysis of the spine symptoms component of the MSK disease activity domain using data from patients with AS in the MEASURE 2 study, secukinumab 150 mg demonstrated greater improvements than placebo in all 3 BASDAI measures [mean change from baseline: -2.19 vs -0.85 , $\mathrm{p}<0.001 ; 20 \%$ improvement: $71.6 \%$ vs $37.5 \%, \mathrm{p}<0.0001$; and adequately controlled disease (score $<4$ ): $46.3 \%$ vs $18.8 \%, \mathrm{p}=0.0008]$ and in achievement of ASAS40 response (36.1\% vs $10.8 \%$; $\mathrm{p}=0.0003$; Figure 2D; Appendix 1).

Personal non-commercial use only. The Journal of Rheumatology Copyright @ 2020 . All rights reserved. 
Table 2. Pooled baseline characteristics of patients in the FUTURE 2, 3, 4, and 5 trials.

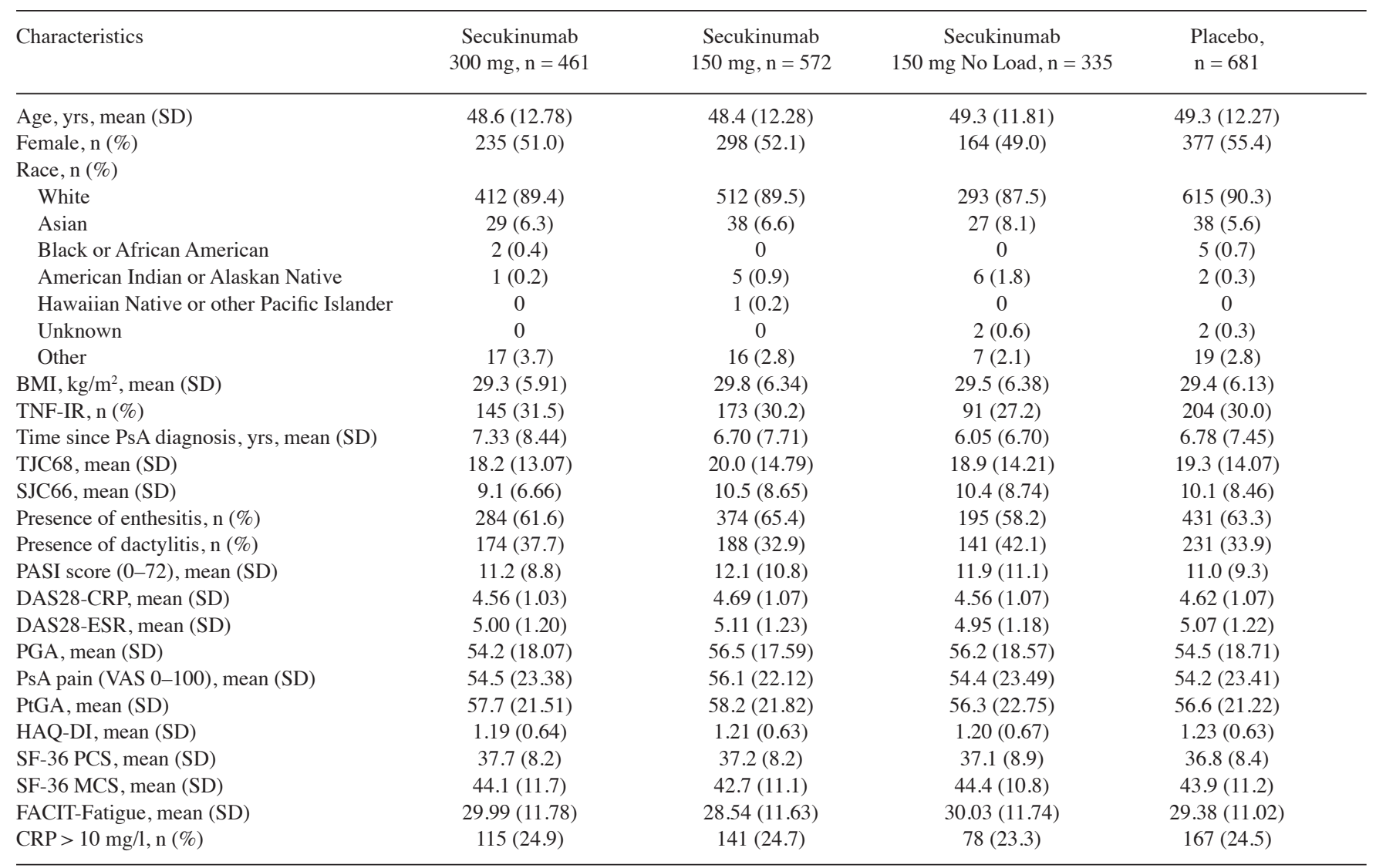

BMI: body mass index; CRP: C-reactive protein; DAS28: 28-joint count Disease Activity Score; ESR: erythrocyte sedimentation rate; FACIT-Fatigue: Functional Assessment of Chronic Illness Therapy-Fatigue; HAQ-DI: Health Assessment Questionnaire-Disability Index; MCS: mental component summary; PASI: Psoriasis Area and Severity Index; PCS: physical component summary; PGA: physician's global assessment; PsA: psoriatic arthritis; PtGA: patient's global assessment; SF-36: Medical Outcomes Study Short Form-36 health survey; SJC66: swollen joint count based on 66 joints; TJC68: tender joint count based on 68 joints; TNF-IR: tumor necrosis factor inadequate responder; VAS: visual analog scale.

Significant improvement was seen in all secukinumab dose groups across the pain, PtGA, and physical function domains (Figure 3A; Appendix 1). Patients who received secukinumab $300 \mathrm{mg}(53.4 \%)$, secukinumab $150 \mathrm{mg}$ (50.2\%), and secukinumab $150 \mathrm{mg}$ no load $(50.4 \%)$ were all significantly more likely to achieve $\mathrm{a} \geq 30 \%$ improvement in pain VAS scores versus those who received placebo (28.6\%; all $\mathrm{p}$ vs placebo $<0.001)$. Patients who received secukinumab $300 \mathrm{mg}$ also had the greatest mean change from baseline $(-19.75)$ in the PsA pain domain compared with placebo (-4.46), though significant improvements vs placebo were also observed for secukinumab $150 \mathrm{mg}(-15.94)$ and secukinumab $150 \mathrm{mg}$ no load (-15.44; all $\mathrm{p}$ vs placebo $<0.0001$; Appendix 1). Similarly, patients who received secukinumab $300 \mathrm{mg}$ (54.0\%), secukinumab $150 \mathrm{mg}$ (49.5\%), and secukinumab $150 \mathrm{mg}$ no load $(45.7 \%)$ were all significantly more likely to achieve $\mathrm{a} \geq 30 \%$ improvement in PtGA from baseline versus those who received placebo (28.0\%; all $\mathrm{p}$ vs placebo $<0.001)$. In addition, $57.1 \%$ of patients who received secukinumab $300 \mathrm{mg}, 51.3 \%$ of patients who received secukinumab $150 \mathrm{mg}$ no load, and
$49.2 \%$ of patients who received secukinumab $150 \mathrm{mg} \mathrm{had}$ clinically meaningful improvement in HAQ-DI $\geq 0.35$, compared with $33.2 \%$ of patients who received placebo (all $\mathrm{p}$ values vs placebo were $\mathrm{p}<0.003$ ). The greatest mean change from baseline in PtGA and HAQ-DI was also seen in patients who received secukinumab $300 \mathrm{mg}$ (Appendix 1).

Regarding HRQOL, the percentage of patients who achieved an MCID in SF-36 PCS and SF-36 MCS (improvement $\geq 2.5$ points) was similar across all 3 secukinumab groups (range 48.4-65.9\%), and all groups were significantly more likely to achieve HRQOL responses than the placebo group (range 40.4-42.0\%; all p values vs placebo $<0.005$; Figure 3B). Similar results were seen in the mean change from baseline for PsAQOL (Appendix 1). In addition, patients who received secukinumab $300 \mathrm{mg}$ had the greatest mean change from baseline $(-7.11)$ in the DLQI score, though patients who received secukinumab $150 \mathrm{mg}$ (-6.57) and secukinumab $150 \mathrm{mg}$ no load (-6.29) also had significantly greater changes from baseline compared with placebo $(-2.14$; all $\mathrm{p}$ vs placebo $<0.0001$; Appendix 1$)$.

Improvement was also seen in all secukinumab dose 

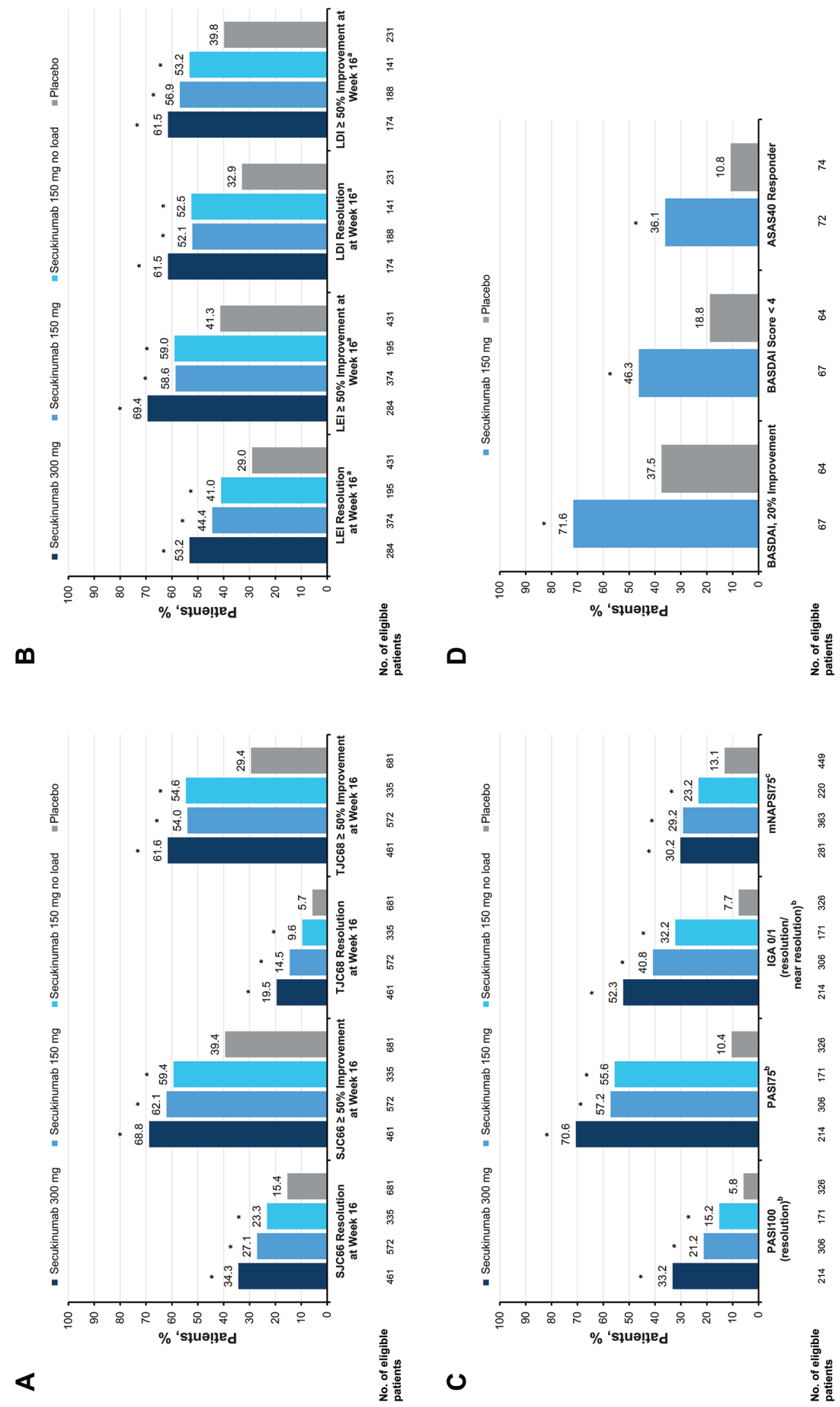

Personal non-commercial use only. The Journal of Rheumatology Copyright $($ C 2020. All rights reserved. 
Figure 2. Percentage of patients with improvement across the musculoskeletal disease activity domain regarding (A) arthritis and (B) enthesitis and dactylitis; (C) percentage of patents with skin and nail responses at Week 16; and (D) improvement in spinal symptoms at Week 16 among patients with ankylosing spondylitis in MEASURE 2. * $\mathrm{p}<0.05$ vs placebo. ${ }^{\mathrm{a}}$ Among patients with enthesitis or dactylitis at baseline only. ${ }^{\mathrm{b}}$ Among patients with BSA $\geq 3 \%$ at baseline. ${ }^{c}$ Among patients with nail involvement at baseline. ASAS40: 40\% improvement in Assessment in SpondyloArthritis international Society response criteria; BASDAI: Bath Ankylosing Spondylitis Disease Activity Index; BSA: body surface area; IGA: Investigator's Global Assessment modified 2011; LDI: Leeds Dactylitis Index; LEI: Leeds Enthesitis Index; mNAPSI75: 75\% improvement in the modified Nail Psoriasis Severity Index; PASI75/100: 75\%/100\% improvement in the Psoriasis Area and Severity Index; SJC66: swollen joint count based on 66 joints; TJC68: tender joint count based on 68 joints.

groups across the fatigue domain, with the secukinumab 300-mg dose group demonstrating the greatest improvement in the FACIT-Fatigue mean change from baseline; although, the FACIT-Fatigue responder data (i.e., the proportion of patients with $\mathrm{a} \geq 3.5$-point change from baseline) showed that both 150-mg dose groups had a numerically higher proportion of patients who achieved a response than the 300-mg group (Figure 3B; Appendix 1). For the systemic inflammation domain, resolution of elevated CRP levels among patients with baseline CRP $>10 \mathrm{mg} / \mathrm{l}$ was observed in $74.8 \%$ of patients in the secukinumab 300-mg group, $69.3 \%$ of patients in the secukinumab $150-\mathrm{mg}$ no load group, $64.2 \%$ of patients in the secukinumab 150-mg group, and $35.7 \%$ of patients in the placebo group (all p vs placebo $<0.0001$; Figure 3B).

Efficacy of secukinumab across GRAPPA-OMERACT PSA middle circle domains. Within the middle circle domains, the secukinumab $300 \mathrm{mg}(-13.98 \%)$, secukinumab $150 \mathrm{mg}$ $(-10.85)$, and $150 \mathrm{mg}$ no-load $(-13.39 \%)$ groups had significantly greater improvements from baseline, as assessed by the WPAI:GH domain of overall activity impairment, compared with placebo $(-4.62 \%$; all p vs placebo $<0.0001$; Figure 4A). In FUTURE 5, there was no structural progression at Week 24 in $88.0 \%$ of patients who received secukinumab $300 \mathrm{mg}$ (p vs placebo <0.0001), 83.8\% of patients who received secukinumab $150 \mathrm{mg}$ no load (p vs placebo $=0.0053$ ), $79.8 \%$ of patients who received secukinumab $150 \mathrm{mg}$, and $73.6 \%$ of patients in the placebo group (Figure 4B).

\section{DISCUSSION}

Psoriatic disease affects not only joints but also the entheses, digits, spine, skin, and nails, leading to heterogeneous clinical phenotypes. The pain, disability, and fatigue associated with PsA significantly affect QOL ${ }^{2}$.

Owing to the characteristics of the disease, assessment of PsA is complex. Clinical trials, to be both feasible and informative, have to balance parsimony and comprehensiveness in their assessment of treatment efficacy. The ACR response indices do not address all domains of PsA; as a result, there has been insufficient granularity to support PsA-specific effects, which has led to the addition of disease-specific endpoints such as psoriasis, enthesitis, and dactylitis, and disease-specific HRQOL. Composite indices developed by the GRAPPA-OMERACT group through consensus between PsA experts pooled different PsA core domains from patients' and physicians' perspectives, which can comprehensively illustrate the efficacy of treatments ${ }^{4}$; however, this is a core domain set and not a core instrument set, with the latter currently in development. Therefore, in our study, we used the instruments recorded in development in clinical trials that reflect the PsA core domains to better understand individual PsA domain responses to secukinumab treatment at various stringency thresholds, including resolution of MSK and skin disease.

The IL-17A pathway plays a key role in the pathogenesis of all manifestations observed in PsA. In patients with PsA, increased levels of cells that produce IL-17A, which have been shown to correlate with measures of disease activity and structural damage, are seen in the circulation, joints, and skin plaques ${ }^{29}$. Secukinumab is a human immunoglobulin G1 monoclonal antibody that selectivity binds to and neutralizes IL-17A and has shown significant efficacy in a number of immune-mediated inflammatory diseases, including PsA and $\mathrm{AS}^{11,12,13,14,15,16}$. Pathogenesis studies have shown differential cytokine pathway expression across tissues, and it is important that the effect of a given mechanism of action is considered across discrete tissues and disease activity domains ${ }^{7}$.

This posthoc analysis examined pooled data from 4 phase III studies of secukinumab for the treatment of PsA [FUTURE 2 ( $\mathrm{N}=397)$, FUTURE 3 ( $\mathrm{N}=414)$, FUTURE 4 $(\mathrm{N}=341)$, and FUTURE $5(\mathrm{~N}=996)]^{11,12,13,14}$. Individually, these studies have shown that treatment with secukinumab leads to significantly higher ACR20 response rates at Week 16 compared with placebo. However, this pooled analysis used multiple instruments to assess the heterogeneous features of PsA observed in clinical practice, demonstrating that secukinumab resulted in robust efficacy across all GRAPPA-OMERACT PsA core domains including resolution of arthritis (i.e., swollen and tender joint counts, dactylitis, and enthesitis). Overall, treatment with secukinumab showed statistically significant efficacy across all PsA core domains compared with placebo at Week 16 (Week 24 for structural damage), with secukinumab 300 mg showing numerically the greatest efficacy across most domains. Among patients who received secukinumab 300 $\mathrm{mg},>50 \%$ achieved complete resolution of enthesitis, and $>60 \%$ achieved complete resolution of dactylitis at Week 16.

In addition, this analysis examined improvements in spine symptoms domain at Week 16 in patients in the MEASURE 2 study. These data showed significant improvements in patients treated with secukinumab $150 \mathrm{mg}$ compared with

Personal non-commercial use only. The Journal of Rheumatology Copyright (C) 2020. All rights reserved. 


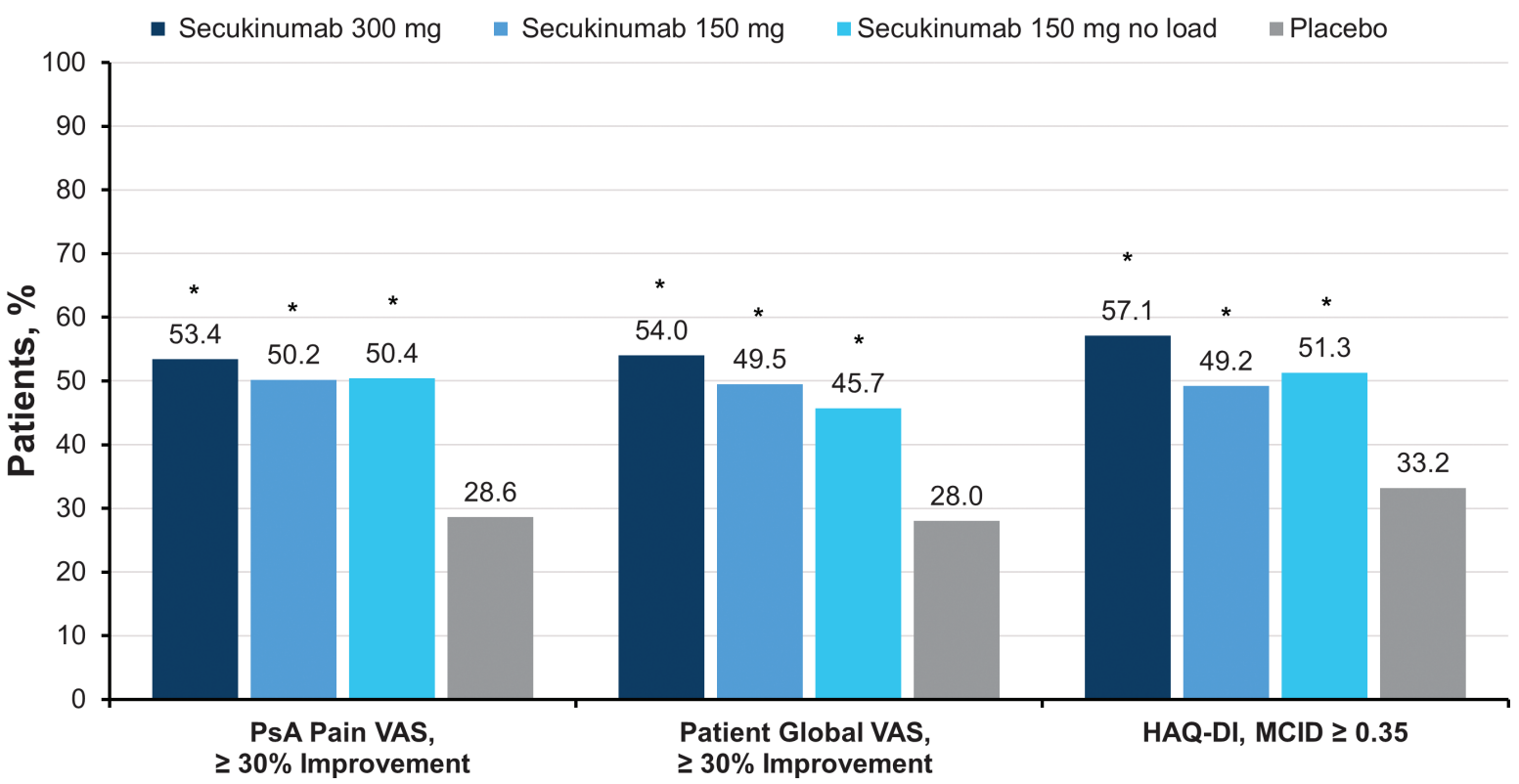

No. of eligible patients

$\begin{array}{llll}461 & 572 & 335 & 681\end{array}$

$572 \quad 335 \quad 681$

$459 \quad 571 \quad 335$

680

\section{B}

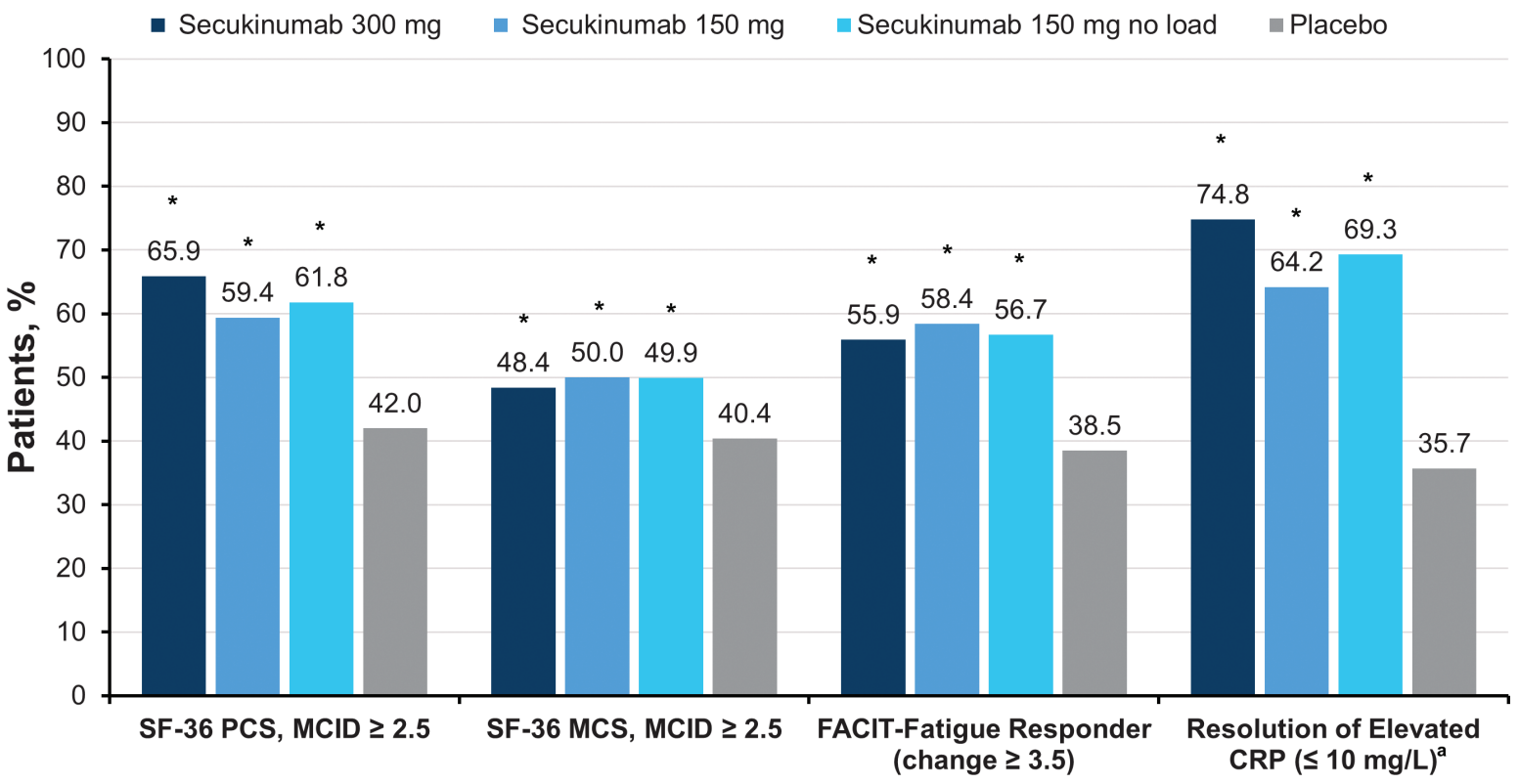

No. of eligible patients

$\begin{array}{llll}461 & 572 & 335 & 681\end{array}$

$\begin{array}{llll}461 & 572 & 335 & 681\end{array}$

$\begin{array}{llll}442 & 546 & 319 & 621\end{array}$

$111 \quad 134 \quad 75 \quad 154$

Figure 3. Percentage of patients with (A) meaningful improvement across pain, patient global, and physical function domains; and (B) improvement at MCID levels across HRQOL, fatigue, and systemic inflammation domains at Week 16 . ${ }^{*} \mathrm{p}<0.05$ vs placebo. ${ }^{a}$ Among patients with $\mathrm{CRP}>10$ mg/l at baseline. CRP: C-reactive protein; FACIT-Fatigue: Functional Assessment of Chronic Illness-Fatigue; HAQ-DI: Health Assessment Questionnaire-Disability Index; MCID: minimal clinically important difference; MCS: mental component summary; PCS: physical component summary; PsA: psoriatic arthritis; SF-36: Medical Outcomes Study Short Form-36 health survey; VAS: 100-mm visual analog scale; HRQOL: health-related quality of life.

\section{Personal non-commercial use only. The Journal of Rheumatology Copyright (C) 2020. All rights reserved.}


those treated with placebo. We acknowledge that data from patients with AS in MEASURE 2 may not be fully representative of data from patients with axial PsA; however, these results are helpful for the purpose of hypothesis generation in the absence of existing axial data in PsA. A forthcoming study (MAXIMISE; NCT02721966) will provide results on the efficacy and safety of secukinumab in patients with active PsA with axial skeletal involvement. Topline data showed that ASAS20 response rates were significantly higher among patients treated with secukinumab $300 \mathrm{mg}$ or $150 \mathrm{mg}$ compared with placebo $(63.1 \%$ and $66.3 \%$ vs $31.3 \% ; \mathrm{p}<0.0001)^{30}$.

This analysis indicates that secukinumab improves all pathophysiological disease manifestations and QOL of patients with active PsA as demonstrated using the GRAPPA-OMERACT PsA core domain set, in addition to already-demonstrated efficacy based on ACR response criteria. The core domain set is important for its content validity to both patients and physicians, and in a disease as complex and heterogeneous as PsA, the core set can serve as the reference point to illustrate the spectrum of disease and response to treatment for individuals ${ }^{31}$. These results demonstrate the added value of secukinumab in improving both disease manifestations and QOL of patients with PsA using the PsA core domain set.

\section{ACKNOWLEDGMENT}

Support for third-party writing assistance for this manuscript, furnished by Eric Deutsch, PhD, CMPP, of Health Interactions Inc., was provided by Novartis Pharmaceuticals Corp.

\section{REFERENCES}

1. Alinaghi F, Calov M, Kristensen LE, Gladman DD, Coates LC, Jullien D, et al. Prevalence of psoriatic arthritis in patients with psoriasis: a systematic review and meta-analysis of observational and clinical studies. J Am Acad Dermatol 2019;80:251-65.

2. Ritchlin CT, Colbert RA, Gladman DD. Psoriatic arthritis. N Engl J Med 2017:376:2095-6.

3. Mease PJ. Measures of psoriatic arthritis: Tender and Swollen Joint Assessment, Psoriasis Area and Severity Index (PASI), Nail Psoriasis Severity Index (NAPSI), Modified Nail Psoriasis Severity Index (mNAPSI), Mander/Newcastle Enthesitis Index (MEI), Leeds Enthesitis Index (LEI), Spondyloarthritis Research Consortium of Canada (SPARCC), Maastricht Ankylosing Spondylitis Enthesis Score (MASES), Leeds Dactylitis Index (LDI), Patient Global for Psoriatic Arthritis, Dermatology Life Quality Index (DLQI), Psoriatic Arthritis Quality of Life (PsAQOL), Functional Assessment of Chronic Illness Therapy-Fatigue (FACIT-F), Psoriatic Arthritis Response Criteria (PsARC), Psoriatic Arthritis Joint Activity Index (PsAJAI), Disease Activity in Psoriatic Arthritis (DAPSA), and Composite Psoriatic Disease Activity Index (CPDAI). Arthritis Care Res 2011;63 Suppl 11:S64-85.

4. Orbai AM, de Wit M, Mease P, Shea JA, Gossec L, Leung YY, et al. International patient and physician consensus on a psoriatic arthritis core outcome set for clinical trials. Ann Rheum Dis 2017; 76:673-80.
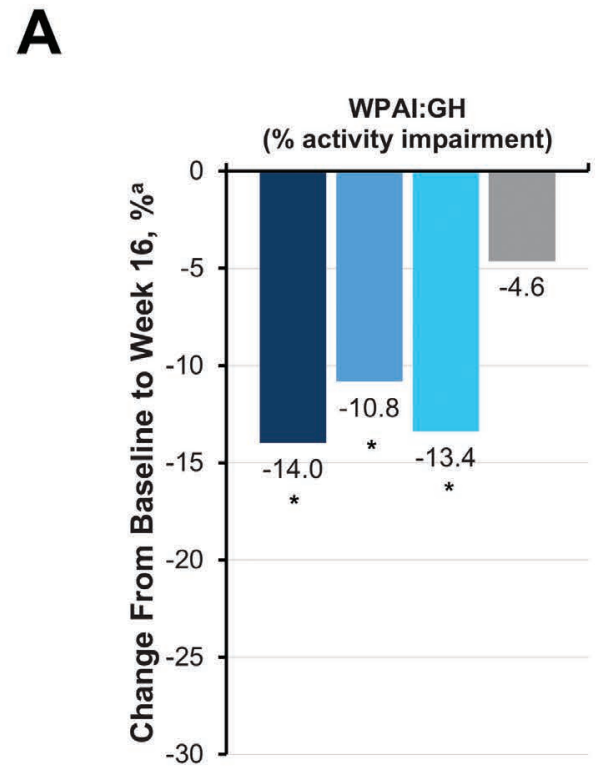

B

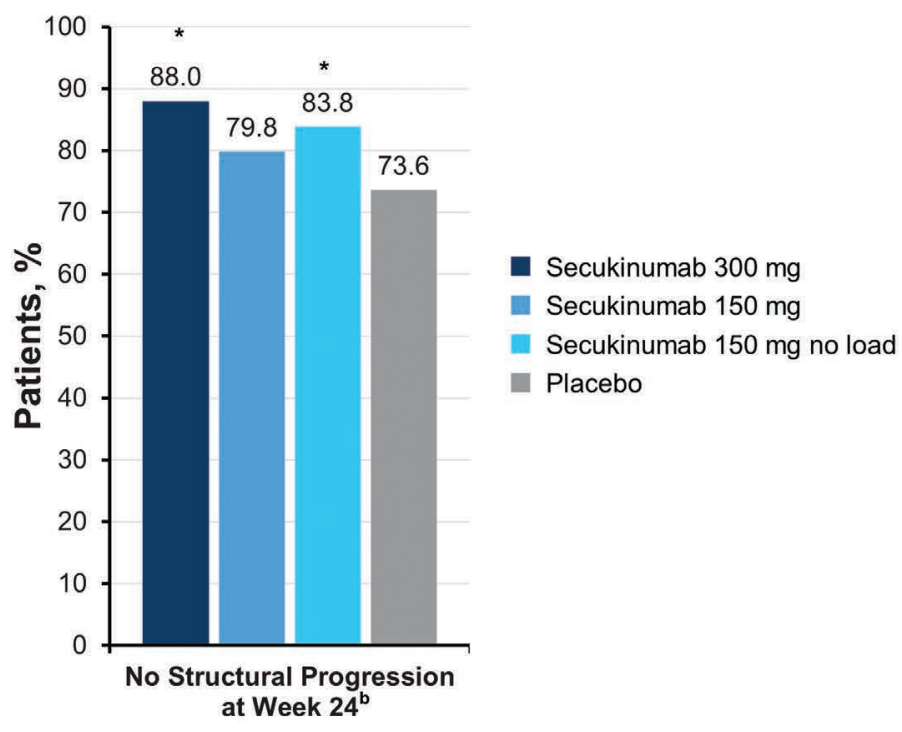

No. of eligible patients $\begin{array}{llll}283 & 392 & 186 & 417\end{array}$

\section{No. of eligible} patients

Figure 4. Percentage of patients with (A) improvement in the participation domain at Week 16 in FUTURE 2-5, and (B) radiographic nonprogression at Week 24 in FUTURE 5. ${ }^{*} \mathrm{p}<0.05$ vs placebo. ${ }^{a}$ Least squares mean change from baseline; $\mathrm{n}$ is the number of patients with measures at both baseline and Week 16 visit. ${ }^{b}$ Data shown are from the FUTURE 5 study only. No structural progression was defined as a change from baseline vdH-mTSS of $\leq 0.5$. WPAI:GH: Work Productivity and Activity Impairment Questionnaire: General Health; vdH-mTSS: van der Heijde-modified total Sharp score. 
5. Gladman DD, Mease PJ, Strand V, Healy P, Helliwell PS, Fitzgerald $\mathrm{O}$, et al. Consensus on a core set of domains for psoriatic arthritis. J Rheumatol 2007;34:1167-70.

6. Orbai AM, de Wit M, Mease PJ, Callis Duffin K, Elmamoun M, Tillett W, et al. Updating the psoriatic arthritis (PsA) core domain set: a report from the PsA workshop at OMERACT 2016. J Rheumatol 2017;44:1522-8.

7. Menon B, Gullick NJ, Walter GJ, Rajasekhar M, Garrood T, Evans $\mathrm{HG}$, et al. Interleukin-17+CD8+ T cells are enriched in the joints of patients with psoriatic arthritis and correlate with disease activity and joint damage progression. Arthritis Rheumatol 2014; 66:1272-81

8. Kirkham BW, Kavanaugh A, Reich K. Interleukin-17A: a unique pathway in immune-mediated diseases: psoriasis, psoriatic arthritis and rheumatoid arthritis. Immunology 2014;141:133-42.

9. Gossec L, Smolen JS, Ramiro S, de Wit M, Cutolo M, Dougados $\mathrm{M}$, et al. European League Against Rheumatism (EULAR) recommendations for the management of psoriatic arthritis with pharmacological therapies: 2015 update. Ann Rheum Dis 2016;75:499-510.

10. Coates LC, Kavanaugh A, Mease PJ, Soriano ER, Laura Acosta-Felquer M, Armstrong AW, et al. Group for Research and Assessment of Psoriasis and Psoriatic Arthritis 2015 treatment recommendations for psoriatic arthritis. Arthritis Rheumatol 2016;68:1060-71.

11. McInnes IB, Mease PJ, Ritchlin CT, Rahman P, Gottlieb AB, Kirkham B, et al. Secukinumab sustains improvement in signs and symptoms of psoriatic arthritis: 2 year results from the phase 3 FUTURE 2 study. Rheumatology 2017;56:1993-2003.

12. Nash P, Mease PJ, McInnes IB, Rahman P, Ritchlin CT, Blanco R, et al; FUTURE 3 study group. Efficacy and safety of secukinumab administration by autoinjector in patients with psoriatic arthritis: results from a randomized, placebo-controlled trial (FUTURE 3). Arthritis Res Ther 2018;20:47.

13. Kivitz A, Nash P, Tahir H, Everding A, Pellet P, Widmer A, et al; on behalf of the FUTURE 4 Study Group. Arthritis: primary results through 52 weeks from a phase-3 randomized placebo-controlled study (FUTURE 4) [abstract]. J Clin Rheumatol 2018;24:364.

14. Mease P, van der Heijde D, Landewé R, Mpofu S, Rahman P, Tahir $\mathrm{H}$, et al. Secukinumab improves active psoriatic arthritis symptoms and inhibits radiographic progression: primary results from the randomised, double-blind, phase III FUTURE 5 study. Ann Rheum Dis 2018;77:890-7.

15. Baeten D, Sieper J, Braun J, Baraliakos X, Dougados M, Emery P, et al; MEASURE 1 Study Group; MEASURE 2 Study Group. Secukinumab, an interleukin-17A inhibitor, in ankylosing spondylitis. N Engl J Med 2015;373:2534-48.

16. Marzo-Ortega H, Sieper J, Kivitz A, Blanco R, Cohen M, Martin $\mathrm{R}$, et al; Measure 2 Study Group. Secukinumab and sustained improvement in signs and symptoms of patients with active ankylosing spondylitis through two years: results from a phase III study. Arthritis Care Res 2017;69:1020-9.

17. Healy PJ, Helliwell PS. Measuring clinical enthesitis in psoriatic arthritis: assessment of existing measures and development of an instrument specific to psoriatic arthritis. Arthritis Rheum 2008;59:686-91.

18. Helliwell PS, Firth J, Ibrahim GH, Melsom RD, Shah I, Turner DE. Development of an assessment tool for dactylitis in patients with psoriatic arthritis. J Rheumatol 2005;32:1745-50.

19. Langley RG, Feldman SR, Nyirady J, van de Kerkhof P, Papavassilis C. The 5-point Investigator's Global Assessment (IGA) Scale: a modified tool for evaluating plaque psoriasis severity in clinical trials. J Dermatolog Treat 2015;26:23-31.

20. Fries JF, Spitz P, Kraines RG, Holman HR. Measurement of patient outcome in arthritis. Arthritis Rheum 1980;23:137-45.

21. Mease PJ, Woolley JM, Bitman B, Wang BC, Globe DR, Singh A. Minimally important difference of Health Assessment Questionnaire in psoriatic arthritis: relating thresholds of improvement in functional ability to patient-rated importance and satisfaction. J Rheumatol 2011;38:2461-5.

APPENDIX 1. Additional pooled efficacy results across GRAPPA-OMERACT PsA core domains (continuous measures).

Improvement in Patients with PsA at Week 16 in FUTURE Trials

\begin{tabular}{|c|c|c|c|c|c|}
\hline $\begin{array}{l}\text { Select PsA } \\
\text { Core Domain }\end{array}$ & $\begin{array}{l}\text { Measures and Improvement } \\
\text { Definitions }\end{array}$ & $\begin{array}{l}\text { Secukinumab } \\
300 \mathrm{mg}, \mathrm{n}=461\end{array}$ & $\begin{array}{c}\text { Secukinumab } \\
150 \mathrm{mg}, \mathrm{n}=572\end{array}$ & $\begin{array}{c}\text { Secukinumab } \\
150 \mathrm{mg} \text { No Load, } \mathrm{n}=335\end{array}$ & $\begin{array}{l}\text { Placebo, } \\
\mathrm{n}=681\end{array}$ \\
\hline Pain & PsA pain, mean change from $\mathrm{BL}(\mathrm{SE})^{\mathrm{b}, \mathrm{c}}$ & $-19.75(1.11), \mathrm{n}=440$ & $-15.94(0.98), \mathrm{n}=545$ & $-15.44(1.32), \mathrm{n}=320$ & $-4.46(0.93), \mathrm{n}=616$ \\
\hline Physical func & 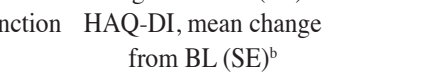 & $-0.48(0.02), \mathrm{n}=438$ & $-0.36(0.02), \mathrm{n}=544$ & $-0.40(0.03), \mathrm{n}=320$ & $-0.16(0.02), \mathrm{n}=615$ \\
\hline Fatigue & FACIT-Fatigue, mean change from $\mathrm{BL}^{\mathrm{b}, \mathrm{c}}$ & $6.21, n=442$ & $5.26, \mathrm{n}=546$ & $5.42, \mathrm{n}=319$ & $1.79, \mathrm{n}=621$ \\
\hline
\end{tabular}

Improvement in Patients with Ankylosing Spondylitis at Week 16 in MEASURE 2a,

Spine symptoms BASDAI, mean change

Secukinumab $150 \mathrm{mg}, \mathrm{n}=72$

$-2.19(0.25)$

from BL (SD)
Placebo, $\mathrm{n}=74$

$-0.85(0.25)$

\footnotetext{
${ }^{a}$ All $\mathrm{p}$ values vs placebo were $\mathrm{p}<0.05$. All $\mathrm{p}$ values were for hypothesis generation. No adjustment was made for multiple comparisons. ${ }^{\mathrm{b}}$ Least squares mean change from BL; $n$ is the number of patients with measures at both BL and Week 16 visit. ${ }^{c}$ No MCID has been defined in PsA. ${ }^{d}$ Baeten D, et al. N Engl J Med 2015;373:2534-48. BASDAI: Bath Ankylosing Spondylitis Disease Activity Index; BL: baseline; DLQI: Dermatology Life Quality Index; FACIT-Fatigue:FunctionalAssessment of Chronic IllnessTherapy-Fatigue scale; GRAPPA:GroupforResearchandAssessment of Psoriasis and PsoriaticArthritis; HAQ-DI: Health Assessment Questionnaire-Disability Index; HRQOL: health-related quality of life; OMERACT: Outcome Measures in Rheumatology; PsA: psoriatic arthritis; PsAQOL: PsA-specific quality of life; PtGA: patient's global assessment; SE: standard error; MCID: minimal clinically important difference.
}

Personal non-commercial use only. The Journal of Rheumatology Copyright @ 2020 . All rights reserved. 
22. Husted JA, Gladman DD, Farewell VT, Long JA, Cook RJ. Validating the SF-36 health survey questionnaire in patients with psoriatic arthritis. J Rheumatol 1997;24:511-7.

23. Kosinski M, Zhao SZ, Dedhiya S, Osterhaus JT, Ware JE Jr. Determining minimally important changes in generic and disease-specific health-related quality of life questionnaires in clinical trials of rheumatoid arthritis. Arthritis Rheum 2000;43:1478-87.

24. Strand V, Burmester GR, Ogale S, Devenport J, John A, Emery P. Improvements in health-related quality of life after treatment with tocilizumab in patients with rheumatoid arthritis refractory to tumour necrosis factor inhibitors: results from the 24-week randomized controlled RADIATE study. Rheumatology 2012;51:1860-9.

25. Strand V, Kremer J, Wallenstein G, Kanik KS, Connell C, Gruben $\mathrm{D}$, et al. Effects of tofacitinib monotherapy on patient-reported outcomes in a randomized phase 3 study of patients with active rheumatoid arthritis and inadequate responses to DMARDs. Arthritis Res Ther 2015;17:307.

26. Finlay AY, Khan GK. Dermatology Life Quality Index (DLQI)--a simple practical measure for routine clinical use. Clin Exp Dermatol 1994;19:210-6.

27. McKenna SP, Doward LC, Whalley D, Tennant A, Emery P, Veale DJ. Development of the PsAQoL: a quality of life instrument specific to psoriatic arthritis. Ann Rheum Dis 2004;63:162-9.

28. Chandran V, Bhella S, Schentag C, Gladman DD. Functional assessment of chronic illness therapy-fatigue scale is valid in patients with psoriatic arthritis. Ann Rheum Dis 2007;66:936-9.

29. Mease PJ, McInnes IB, Kirkham B, Kavanaugh A, Rahman P, van der Heijde D, et al; FUTURE 1 Study Group. Secukinumab inhibition of interleukin-17A in patients with psoriatic arthritis. N Engl J Med 2015;373:1329-39.

30. Baraliakos X, Coates LC, Gossec L, Jeka S, Varela AM, Schulz B, et al. Secukinumab improves axial manifestations in patients with psoriatic arthritis and inadequate response to NSAIDs: primary analysis of the MAXIMISE trial [abstract]. Ann Rheum Dis 2019;78:195-6.

31. Felson DT, LaValley MP. The ACR20 and defining a threshold for response in rheumatic diseases: too much of a good thing. Arthritis Res Ther 2014;16:101. 